\title{
Como os gestores têm aprendido sobre a rotina de gerenciamento do processo produtivo dos pedidos dos clientes?
}

\section{How have managers learned about the application of monitoring routine?}

\author{
Soraya Sales dos Santos e Silva \\ Eduardo de Aquino Lucena ${ }^{1}$
}

\begin{abstract}
Resumo: Este artigo teve como objetivo compreender como gestores aprenderam a exercer a rotina de gerenciamento do processo produtivo dos pedidos dos clientes. O estudo fundamentou-se teoricamente nas abordagens da perspectiva da aprendizagem pela experiência e da vertente da estratégia como prática. Um estudo de caso qualitativo foi realizado na metalúrgica Maxtil. Dados foram coletados por meio de entrevistas, documentos e observação. A análise compreendeu a descrição e interpretação dos dados, para a formação de categorias. Concluiu-se que os gestores aprenderam sobre a rotina estudada por meio da vivência de situações, da busca de informações, da interação com pessoas e da reflexão.

Palavras-chave: Aprendizagem de gestores; Aprendizagem pela experiência; Estratégia como prática; Rotinas organizacionais; Cadeia produtiva de petróleo e gás e da Indústria Naval.
\end{abstract}

\begin{abstract}
This article aims to understand how managers have learned to exercise the production process management routine related to customer orders. The study was based on theoretical approaches from the perspective of 'learning through experience' and 'strategy as practice'. A qualitative case study was conducted at Maxtil metallurgical company. Data were collected through interviews, documents, and observation. The analysis included the description and interpretation of data for the formation of categories. We conclude that managers have learned about the monitoring routine by experiencing situations, searching for information, interacting with people, and reflecting.
\end{abstract}

Keywords: Managers' learning; Learning through experience; Strategy as practice; Organizational routines; Oil, gas and Shipbuilding Industry supply chain.

\section{Introdução}

A complexidade e a dinamicidade são algumas das características mais latentes do mundo moderno. Ao se ponderar sobre a primeira década do século XXI, observa-se que o ser humano deixou de ser controlado apenas pela ordem econômica. Iniciou-se uma era em que o conhecimento assume um espaço de destaque dentro das relações de poder que regem o mercado.

Nesse cenário, a aprendizagem dos gestores torna-se importante à medida que se percebe o quão multifacetado deve ser o seu conhecimento para que os obstáculos presentes na trajetória para o crescimento de uma organização sejam superados. Como consequência da velocidade da mudança tecnológica - inovações na comunicação, como a Internet, que forçam as organizações e os indivíduos a adaptarem-se rapidamente a situações diversas - " [...] firmas não podem depender de práticas estabelecidas, elas precisam forjar novos processos e tecnologias: em outras palavras, elas precisam aprender novas formas de fazer as coisas [...] " (Easterby-Smith et al., 1998, p. 260). Dessa forma, torna-se latente a necessidade de os gestores aprenderem a lidar com assuntos diversos e atividades estratégicas para o funcionamento da organização.

Este artigo se propõe a apresentar uma abordagem inicial sobre a aprendizagem de gestores sobre as práticas de estratégia, mais especificamente, sobre a rotina de gerenciamento do processo produtivo dos pedidos dos clientes. $\mathrm{O}$ artigo tem como objetivo entender como os gestores investigados aprenderam a exercer tal rotina. A fim de atingir este objetivo, foram utilizadas duas abordagens teóricas centrais, a aprendizagem pela experiência e a estratégia como

${ }^{1}$ Programa de Pós-Graduação em Administração, Departamento de Ciências Administrativas, Universidade Federal de Pernambuco - UFPE, Av. Prof. Moraes Rego, 1235, Cidade Universitária, CEP 50670-901, Recife, PE, Brasil, e-mail: soso_sales@hotmail.com; eaqlucena@yahoo.com.br 
prática. Complementarmente, buscaram-se conceitos nas áreas de estudo das Rotinas Organizacionais e da Gestão da Produção. A pergunta de pesquisa que guiou a investigação foi: como os gestores têm aprendido sobre a rotina de gerenciamento do processo produtivo dos pedidos dos clientes? É relevante destacar que a referida rotina foi indicada pelos respondentes desta pesquisa como sendo uma prática de estratégia ligada à gestão da qualidade da organização na qual atuavam.

A temática da aprendizagem mostra-se relevante para diversas áreas do saber. Além de ser objeto de investigação recorrente nos campos da Administração e da Sociologia, também tem sido estudada na área da Engenharia da Produção. Estudos como os de Gonzalez \& Martins (2011) e Loiola et al. (2011) evidenciam a importância do processo de aprendizagem de rotinas relacionadas à gestão da qualidade nas organizações e revelam o quão estratégica essa variável pode ser para uma atuação de sucesso em mercados competitivos.

Para o desenvolvimento do presente estudo, foi selecionada uma organização fornecedora da cadeia produtiva de Petróleo e Gás e da Indústria Naval de Pernambuco, a Maxtil Indústria e Comércio Ltda., metalúrgica de médio porte - seguindo a classificação do BNDES. A cadeia produtiva em questão tem apresentado um grande crescimento no Estado de Pernambuco, especialmente desde o ano de 2007, quando se iniciaram os investimentos para construção da Refinaria Abreu e Lima, do polo têxtil e de embalagens e do Estaleiro Atlântico Sul. Essa cadeia envolve grandes investimentos em maquinário, mão de obra qualificada, estrutura, entre outros, por isso, o padrão de qualidade exigido aos fornecedores de bens materiais é elevado. Por ser uma demanda recente, alcançar os níveis de qualidade exigidos pela cadeia produtiva requer, por parte dos gestores uma rápida resposta ao mercado, de modo que as oportunidades de expansão e crescimento possam ser aproveitadas. Desse modo, os gestores assumem papel relevante no desempenho das organizações e compreender a aprendizagem que ocorre nesse processo de adaptação às demandas do mercado pode acarretar o desenvolvimento de uma contribuição real para os empresários locais.

\section{Fundamentação teórica}

A fundamentação teórica deste estudo baseia-se em textos da abordagem da aprendizagem pela experiência e da vertente da estratégia como prática. O campo da aprendizagem pela experiência e a vertente da estratégia como prática compartilham a ideia de que tanto uma quanto outra são, em sua essência, práticas sociais. Lave \& Wenger (1991) atestam que, como um aspecto da prática social, aprendizagem envolve a pessoa como um todo; isso implica não somente uma relação com atividades específicas, mas uma relação com comunidades sociais. De modo semelhante, Whittington (2007) atesta que a estratégia como prática possui uma riqueza de investigações por causa de seu insight-chave: a estratégia é uma prática social que possui muitas facetas e ramificações, sendo, assim, mais ampla, podendo fazer a diferença para a sociedade. Nesse sentido segue uma explanação dessas perspectivas.

\subsection{Aprendizagem pela experiência}

Este estudo adota uma lente construtivista para a investigação do fenômeno da aprendizagem. Segundo Merriam \& Caffarella (1999), essa orientação não vê o processo de aprendizagem apenas como uma resposta aos estímulos do ambiente, a algo externo ao indivíduo, mas sim como uma constante construção, um processo de atribuição de significados às situações vividas, assim como de ressignificação. Os pesquisadores que adotam esse paradigma, construtivista, especialmente nas ciências sociais, compartilham o "[...] objetivo de entender o mundo complexo de experiências vividas do ponto de vista daqueles que nele vivem." (Schwandt, 1994, p. 118).

As definições de aprendizagem podem variar de acordo com o contexto e com a visão adotada na investigação. Elkjaer (2004) destaca a existência de duas vias por meio das quais pode ocorrer a aprendizagem organizacional, a da aquisição e a da participação - que se referem à transferência do conhecimento e à aprendizagem como construção social, respectivamente - para, então, propor o terceiro modo de aprendizagem. Para ela, a aprendizagem organizacional é vista como uma combinação de habilidades e aquisição de conhecimento (resultado) e participação em comunidades de prática (processo). Assim, a autora sugere que o entendimento filosófico e educacional de Dewey e seus estudos sobre experiência e pensamento reflexivo - a serem discutidos mais à frente - podem ser úteis para clarificar e expandir o entendimento da aprendizagem dentro da metáfora da participação. Destaca, assim, a possibilidade de esclarecer "como" a aprendizagem ocorre e "o que" é aprendido por meio da participação.

Essa complementação aos estudos já realizados sob a perspectiva da aprendizagem por meio da participação é, para Elkjaer (2004), a base para o desenvolvimento de um terceiro modo de aprendizagem. A autora explica que sua concepção se dá por meio de uma síntese do primeiro e do segundo modo, para reconhecer que "[...] o pensamento é instrumental na aprendizagem como participação e que aprendizagem ocorre como um processo social." (Elkjaer, 2004, p. 420). Adota-se neste artigo a lente proposta por Elkjaer (2004) do "terceiro modo", ou seja, a aprendizagem como uma prática social. 
Para desenvolver esta pesquisa, foi necessário compreender alguns conceitos de Dewey, em especial aqueles que pudessem esclarecer aspectos da aprendizagem dos gestores sobre as rotinas das organizações nas quais atuam. Elkjaer (2009) sugere que o pragmatismo desenvolvido por Dewey é a chave para compreender a aprendizagem no futuro. A autora argumenta que "[...] um olhar mais atento à noção de Dewey sobre experiência pode ser útil para a criação de uma teoria de aprendizagem que responde à necessidade de criatividade e inovação que, pelo menos retoricamente, está na demanda em sociedades do conhecimento contemporâneo." (Elkjaer, 2009, p. 75). Seguindo esse conceito de experiência, o conhecimento é visto como algo "[...] provisório, transitório e sujeito a mudanças ('falível') porque a experiência futura pode agir como um corretivo ao conhecimento existente." (Elkjaer, 2009, p. 75). Nesse sentido, a aprendizagem seria um processo contínuo. Não há certezas, mas sim ideias e conceitos temporariamente aceitos que contribuem para a compreensão daquilo que se vive.

O conceito de aprendizagem pela experiência utilizado neste artigo apoia-se largamente na noção de experiência desenvolvida por Dewey. Segundo Miettinen (2002), do ponto de vista epistemológico, o conceito de experiência é definido como uma representação da aprendizagem e obtenção de conhecimento. Elkjaer (2004) adiciona que, para Dewey, experiência é uma série de coordenações orgânicas conectadas; ela é a transação ou a relação, a contínua formação de indivíduos e ambiente. As experiências, assim, influenciam os indivíduos, atuando como norteadoras das decisões presentes, modificando ou perpetuando suas atitudes em ações futuras.

A influência que as experiências presentes exercem sobre aquelas que ainda estão por vir dependem de sua qualidade. Dewey (1938) explica que a qualidade de qualquer experiência tem dois aspectos, que são representados pelos princípios da continuidade e da interação da experiência. Tais princípios ajudam a distinguir entre as experiências educativas e as não educativas. O primeiro princípio - continuidade - significa que toda experiência tanto tira algo daquela que foi vivenciada antes quanto modifica, de alguma forma, a qualidade daquelas que virão depois. Assim, "[...] toda experiência vive em experiências futuras [...]" (Dewey, 1938, p. 27). O segundo princípio - interação - provê direitos iguais a ambos os fatores da experiência, que são as condições objetivas e as internas. Essas condições, consideradas em conjunto, ou em interação, formam o que se chama de situação. De acordo com Dewey (1938, p. 43), "[...] os conceitos de situação e de interação são inseparáveis um do outro. Uma experiência é o que é por causa da transação que ocorre entre um indivíduo e o que, no momento, constitui seu ambiente." O autor complementa que "[...] o meio ambiente é, em outras palavras, quaisquer condições nas quais se interage com as necessidades pessoais, os desejos, os propósitos e as capacidades para criar a experiência que se tem." (Dewey, 1938, p. 44).

Os estudos de Dewey apontam a existência de experiências reflexivas e não reflexivas. Miettinen (2002) explica que Dewey considera que a experiência não reflexiva - baseada em hábitos - é dominante, e que a experiência reflexiva - mediada por inteligência e conhecimento - cresce a partir da inadequação e da contradição da experiência habitual e dos meios de ação. Em outras palavras, quando o conhecimento adquirido pelo indivíduo na vivência de experiências anteriores não é o bastante para a resolução de um conflito ou tomada de decisão numa situação nova ou inesperada, a reflexão possibilita a aprendizagem do indivíduo, fazendo com que obtenha novos conhecimentos. Jarvis (1987) chama de "disjunção" essa diferença entre o conhecimento necessário para lidar com a nova situação e o conhecimento real que se possui. Nas palavras do autor, “[...] quando há uma disjunção entre a biografia do próprio indivíduo e o mundo sócio-cultural-temporal de sua experiência, então uma potencial aprendizagem pela experiência ocorreu." (Jarvis, 1987, p. 168). Os estudos realizados por Santos (2009) e por Vitório (2008) corroboram Jarvis (1987), uma vez que os resultados encontrados em suas investigações apontaram que a aprendizagem dos gestores ocorre por meio dessas situações de disjunção.

Os conceitos explorados na perspectiva da aprendizagem pela experiência, em especial os trazidos por Dewey em suas obras, contribuem para a compreensão do fenômeno da aprendizagem que pode ocorrer, dentre outros lugares, num ambiente organizacional. Esse ambiente, cada vez mais dinâmico e competitivo, pressiona os executivos no processo de tomada de decisão, exigindo que suas respostas sejam praticamente imediatas, o que reduz significativamente seu tempo disponível para a geração de hipóteses na busca pela solução dos problemas. Inserido nesse contexto, o gestor passa a buscar meios de "aprender a aprender" e a experiência assume um papel importante na formação do conhecimento. Jarvis (1987) argumenta que quando a experiência é significante, torna-se base do aprendizado.

Estudos relativos à aprendizagem podem ser aplicados em diversos contextos. É possível realizar pesquisas multidisciplinares, buscando enriquecer o conhecimento existente acerca do fenômeno em questão. Nesse sentido, para o desenvolvimento desta pesquisa, optou-se pela utilização de alguns conceitos presentes no campo de estudo da estratégia, mais especificamente, da perspectiva "estratégia como prática", que será apresentada na subseção seguinte. 


\subsection{Estratégia com prática}

O foco de investigação da estratégia apresentou algumas mudanças ao longo dos anos. Os estudos realizados, durante muito tempo foram fortemente conduzidos por interesses e teorias econômicas de mercado. Por volta dos anos de 1990, estudiosos do campo da estratégia passaram a investigar as práticas que ocorrem dentro das organizações (Whittington, 1996). Ou seja, aproximaram-se das práticas desempenhadas nas organizações e dos indivíduos que a compõem para compreenderem o trabalho de fazer a estratégia e como se aprende a fazê-lo (Whittington, 1996).

Os estudos desenvolvidos sob essa perspectiva fazem parte de um movimento contemporâneo no campo da estratégia (Jarzabkowski, 2004; Whittington, 2001, 2003, 2006) e têm como foco a estratégia como prática social, em como os profissionais de estratégia agem e interagem. O interesse dessa vertente, segundo Jarzabkowski \& Whittington (2008), é estudar a estratégia por meio das lentes da práxis, praticantes e práticas da estratégia. Termos esses que, de acordo com Whittington (2002), referem-se respectivamente ao trabalho, aos trabalhadores e às ferramentas de estratégia.

As teorias e conceitos advindos da Sociologia sustentam a ideia de que as práticas de estratégia podem ser estudadas como uma prática social, possibilitando que os atores da estratégia sejam analisados a partir de diversos ângulos. Nesse sentido, o trabalho de Whittington (2007) advoga que a estratégia é tratada como uma instituição socialmente integrada, assumindo formas distintas em diferentes sociedades e épocas. $\mathrm{O}$ crescimento no número de estudos dessa natureza tem contribuído para o desenvolvimento da perspectiva da estratégia como prática. Utilizando-se de conceitos do campo da Sociologia para fortalecer suas argumentações, Whittington (2010) afirma que a teoria da estruturação de Anthony Giddens tem um apelo óbvio para os pesquisadores da estratégia como prática, pois os conceitos de estrutura, agência e estruturação por ele desenvolvidos têm importância intrínseca para investigação da prática. Whittington (2010) explica que a concepção de Giddens da agência humana atesta que a prática precisa ser estudada porque ela faz diferença para os resultados e a noção de estrutura social permite tanto restrição quanto capacitação.

A "agência" assemelha-se ao conceito de práxis explorado pela estratégia como prática (Johnson et al., 2007). "Agência refere-se a fazer" (Giddens, 2009, p. 12). Giddens (2009) explica que agência diz respeito a eventos dos quais um indivíduo é perpetrador, no sentido de que ele poderia, em qualquer fase de uma dada sequência de conduta, ter atuado de modo diferente. $\mathrm{E}$ o fato de o ator ser capaz de atuar de outro modo, argumenta Giddens (2009, p. 17), “[...] significa ser capaz de intervir no mundo, ou abster-se de tal intervenção, com o efeito de influenciar um processo ou estado específico das coisas."

Apesar das contribuições fornecidas pelos estudos já realizados, ainda há um vasto campo de pesquisa a ser explorado nas pesquisas que adotam a perspectiva da estratégia como prática. Golsorkhi et al. (2010, p. 13) afirmam que muitas questões ainda merecem esforços de investigação, dentre elas aquelas que estejam relacionadas com a agência da estratégia e o fazer estratégico (strategizing). Assim, entende-se que é relevante explicar os conceitos práticas, práxis e praticantes, pois estão diretamente relacionados com o fazer estratégico.

A utilização dos termos práxis, práticas e praticantes pode ser considerada inseparável dos estudos desenvolvidos na estratégia como prática. Metaforicamente, poder-se-ia dizer que cada termo representa uma peça da engrenagem que faz com que a estratégia ocorra. Esses termos funcionam como conceitos-chave para o entendimento de como é feita a estratégia (Whittington, 2006; Jarzabkowski et al., 2007). Jarzabkowski et al. (2007) acrescentam que a junção dos três elementos constitui o strategizing, que, por sua vez, compreende as ações, interações e negociações dos múltiplos atores e as práticas situadas na realização das atividades.

Este artigo baseia-se na definição de Johnson et al. (2007) para compreender os termos práxis e práticas, que compõem o strategizing. Segundo Johnson et al. (2007, p. 26-27), a práxis é "o que as pessoas fazem" e as práticas são "o que as pessoas se engajam com". Ainda, os autores sugerem a utilização do conceito de rotinas organizacionais desenvolvido por Feldman \& Pentland (2003) para compreender os termos em questão. Feldman \& Pentland (2003) desenvolveram uma definição baseada na teoria da estruturação de Giddens, utilizando os conceitos de estrutura e agência para explicar os dois aspectos que compõem a rotina organizacional, o ostensivo e o performativo. Para os autores, uma rotina organizacional consiste de duas partes, "[...] uma parte incorpora a ideia abstrata da rotina (estrutura), enquanto a outra parte consiste no real desempenho da rotina por pessoas específicas, em tempos específicos, em lugares específicos (agência)." (Feldman \& Pentland, 2003, p. 95).

$\mathrm{O}$ aspecto ostensivo diz respeito aos procedimentos e regras. Assim, entende-se que este constitui a parte formal da rotina, constitui as práticas. Pentland \& Feldman (2005) explicam que esse aspecto da rotina é abstrato ou um padrão generalizado. Participantes o utilizam para guiar, julgar e referir performances específicas da rotina. $\mathrm{O}$ aspecto ostensivo pode ser pensado como uma narrativa, ou um documento. Já o aspecto performativo, refere-se à ação do indivíduo, à execução das regras e dos procedimentos, constitui 
a práxis. Defende-se que "[...] o aspecto performativo da rotina pode ser entendido inerentemente como improvisação. Até mesmo rotinas exercidas pelas mesmas pessoas muitas vezes precisam ser ajustadas para contextos de mudança [...]" (Feldman \& Pentland, 2003, p. 102). Apoiando-se nessa concepção de rotina, utilizam-se neste artigo indistintamente os termos práticas de estratégia e rotinas organizacionais.

\section{Procedimentos metodológicos}

A fim de compreender como ocorre o fenômeno da aprendizagem dentro de uma realidade social e temporal específica, optou-se por utilizar o método qualitativo, que "facilita o estudo de questões em profundidade e detalhes" (Patton, 2002, p. 14). Optou-se, ainda, pela realização de uma pesquisa exploratória, por meio de um estudo de caso único, que, para Yin (2005), pode representar uma importante contribuição à base do conhecimento. Assim, a generalização não é a finalidade deste estudo, mas sim a compreensão do objeto estudado em sua essência, aprofundando o máximo possível o conhecimento sobre o caso.

De acordo com Minayo (2004), o ciclo de pesquisa compõe-se de três momentos: fase exploratória da pesquisa, trabalho de campo e tratamento do material. A primeira etapa deste estudo, fase exploratória, ocorreu por meio de vasta pesquisa bibliográfica sobre o tema da aprendizagem de gestores e das práticas de estratégia, de escolhas metodológicas e da definição de um cronograma de pesquisa. Na segunda fase, trabalho de campo, utilizou-se para a escolha do caso o método não probabilístico. De acordo com Merriam (2009, p. 77), o mesmo pode ser chamado também de intencional ou proposital. $\mathrm{O}$ caso foi selecionado a partir de critérios pré-estabelecidos, seguindo a orientação proposta por Merriam (2009) de que sejam utilizados critérios de escolha em dois níveis - organização e indivíduo.

No nível organizacional, selecionou-se uma organização que: (a) fornecia produtos para a cadeia produtiva em questão; (b) possuía certificações de qualidade; (c) possuía em seu quadro funcional gestores com experiência, que atuassem há, no mínimo, três anos no mercado. Seguindo esses critérios, selecionou-se a Maxtil Indústria e Comércio Ltda. Fez-se necessário, antes de tudo, que a organização fosse acessível aos pesquisadores.

A aplicação dos critérios citados observou os seguintes aspectos: a tecnologia e os procedimentos necessários para produção de insumos; a adoção de normas técnicas de produção como a International Organization for Standardization (ISO) ou, ainda, certificações fornecidas pela Petrobras, como o Certificado de Registro de Classificação Cadastral (CRCC); e o tempo de atuação no mercado, na intenção de que fosse suficiente para obter experiência no exercício das práticas de estratégia.
Depois de estabelecer critérios para escolha dos casos, seguindo a orientação de Merriam (2009), o mesmo foi feito para selecionar quem entrevistar, os pontos a serem observados e quais documentos analisar. Assim, levou-se em consideração para escolha dos respondentes: quantos anos de experiência no setor ele possuía (sendo desejado o mínimo de três anos) e seu período de atuação na organização selecionada (mínimo de um ano). Foram selecionados seis gestores da Maxtil. Não houve distinção em relação ao grau de escolaridade, ao gênero, à nacionalidade ou à idade. No que concerne aos documentos, buscou-se ter acesso àqueles que estivessem ligados aos procedimentos realizados para obtenção e manutenção do CRCC e às práticas de estratégia estabelecidas para a gestão da qualidade.

Esta pesquisa utilizou como principal método para coleta de dados a entrevista semiestruturada, acompanhada de observação não participante e análise documental (Merriam, 2009). Os dados foram coletados em 19 visitas realizadas entre os meses de setembro e dezembro de 2011. Concretamente, essas visitas resultaram em cerca de quarenta horas de convivência no ambiente da organização, das quais mais de dez horas referem-se às entrevistas realizadas e as demais à observação das atividades dos gestores para conhecer o funcionamento dos setores. Complementarmente, os pesquisadores registraram diversas notas de campo ao longo de suas visitas ou, posteriormente, em momentos de reflexão sobre o que haviam observado. Apesar de um período curto de coleta de dados, em comparação a estudos similares sobre o tema das rotinas organizacionais, os pesquisadores buscaram suprir tal limitação utilizando uma rica descrição da rotina estudada, assim como da análise dos dados.

A análise dos dados, fase de tratamento do material (Minayo, 2004), envolveu não só a descrição dos achados, mas também a construção de categorias (Patton, 2002; Merriam, 2009). Assim, o procedimento de análise dos dados para a formação das categorias ocorreu de modo comparativo e gradual, ao longo do desenvolvimento deste estudo. Inicialmente, as doze entrevistas realizadas com os seis gestores selecionados foram transcritas. Realizou-se uma primeira leitura das entrevistas e trechos considerados importantes para o estudo foram destacados. Depois dessa etapa, agruparam-se os trechos destacados de cada entrevista, analisando-se uma a uma, buscando relacionar as partes que apresentassem similaridades. A cada nova entrevista que era analisada, os dados disponíveis eram classificados e reclassificados para a formação das categorias, seguindo o mesmo procedimento de comparação e agrupamento dos trechos destacados. Levaram-se, ainda, em consideração para a formação das categorias as observações feitas, os documentos aos quais se teve acesso e as notas de campo registradas. 


\section{Resultados}

Tendo em vista as diferentes rotinas existentes na Maxtil optou-se por identificar algumas práticas de estratégia específicas que estivessem diretamente ligadas à gestão da qualidade. As rotinas encontradas foram selecionadas por indicação dos próprios respondentes. Cada um dos entrevistados destacou dentre as rotinas que exercia aquela que julgava estar mais ligada à gestão da qualidade. A partir dessas respostas, buscou-se identificar com que frequência essas rotinas ocorriam, quais eram suas ações padrão, quem eram os participantes e quais atividades estavam interligadas a ela. Por meio das observações realizadas e dos depoimentos dos entrevistados, foram identificadas (e nomeadas pelos autores) quatro rotinas: suprimento de matéria-prima, planejamento da produção, gerenciamento do processo produtivo dos pedidos dos clientes e controle de conformidade do produto. Neste artigo, exploram-se os resultados referentes à aprendizagem dos gestores sobre a rotina de gerenciamento do processo produtivo dos pedidos dos clientes, a qual, a partir deste ponto, será chamada de "rotina de gerenciamento dos pedidos".

Para justificar tal escolha, argumenta-se que: (a) mecanismos adequados para acompanhar o pedido permitem que ajustes sejam feitos ao longo do processo produtivo; (b) essa rotina é capaz de assegurar que o pedido seja iniciado e finalizado conforme combinado em termos de quantidade, de qualidade e de prazo; (c) todos os participantes da pesquisa executam ao menos uma etapa da referida rotina; e (d) as demais rotinas identificadas restringem-se a uma parte específica do processo produtivo. Mais concretamente, poder-se-ia dizer que a correta execução da rotina de suprimento de matéria-prima ou planejamento da produção influenciam, mas não asseguram a qualidade no produto final. E a rotina de controle de conformidade do produto está presente apenas no final do processo produtivo. Já a rotina de gerenciamento dos pedidos faz-se presente em todo o processo, interferindo diretamente na qualidade do produto final. Assim, tal rotina constitui uma prática estratégica para a Maxtil, pois reflete na sua relação com os clientes e na sua imagem perante o mercado.

\subsection{Rotina de gerenciamento do processo produtivo dos pedidos dos clientes}

A rotina de gerenciamento dos pedidos envolve os setores de Vendas, de Produção e de Logística. A finalidade dessa rotina é assegurar que o pedido seja produzido e entregue conforme acordado no momento da venda. A ação característica dessa rotina é a cobrança. Foram entrevistados os seguintes atores envolvidos na execução da rotina: Gleyce - Gerente de Vendas; Carlos - Gerente de Produção; Sérgio - Gerente Industrial; Pablo - Encarregado do Planejamento e
Controle da Produção (PCP); e Cícero - Supervisor de Logística. Paulo, Diretor da Maxtil, está envolvido com a rotina de uma forma indireta, por meio de atividades como a supervisão e a cobrança que realiza constantemente aos gestores de cada setor.

É possível destacar algumas etapas presentes na execução da rotina de gerenciamento dos pedidos. Quando uma venda é realizada, (1) o pedido é inserido no sistema e (2) gera-se uma Ordem de Compra que é enviada aos setores de Logística e de Produção. No setor de Logística, (3) verifica-se a disponibilidade dos itens solicitados no estoque. Identificada a necessidade de produção, (4) o setor de Logística gera uma Ordem de Produção e a envia ao referido setor. O setor da Produção, por sua vez, (5) gera as Ordens de Serviço e as distribui pelos setores da fábrica. (6) Os pedidos finalizados são entregues à Logística. Por fim, (7) o setor de Logística realiza o acabamento dos itens, (8) envia os pedidos aos clientes e (9) verifica como os produtos foram recebidos. Ao longo dessas etapas, a fim de obter as informações sobre cada pedido em aberto, Gleyce (Gerente de Vendas) conduz uma reunião diária com os setores envolvidos. A rotina só é finalizada quando o cliente recebe seu pedido.

A rotina de gerenciamento dos pedidos é abrangente. Por ter a função de assegurar a execução do pedido conforme combinado com o cliente em termos de quantidade, qualidade e prazo, a rotina está diretamente ligada a uma adequada gestão da qualidade dos produtos da Maxtil. Outro fator interessante é sua ligação com um evento peculiar dentro da empresa, chamado pelos respondentes de "Virada de Mesa". Em maio de 2011, a Maxtil passava por diversas dificuldades e Paulo, o Diretor, já havia buscado várias formas de resolver os problemas, mas não obteve sucesso. Ele relatou que chegou a ter pedidos com atraso de mais de três meses e o cliente não cancelava o pedido. O Diretor explicou que após ponderar sobre diversas alternativas, recordou-se de um livro de Ricardo Semler que havia lido na década de 1980, "Virando a Própria Mesa", e concluiu que deveria realizar uma Virada de Mesa na sua própria empresa. Então, Paulo convocou os funcionários responsáveis por cada setor para uma reunião extraordinária, na qual apresentou a real situação da Maxtil. O intuito da reunião era trazer para os funcionários um senso de responsabilidade por aquela situação e mostrar-lhes que a mudança daquele quadro dependia do comprometimento de cada um em suas respectivas funções. Nesse dia, Paulo propôs a criação de algumas rotinas específicas para organizar as atividades dos setores, dentre elas, a rotina de gerenciamento dos pedidos. Esse evento causou uma mudança significativa na empresa. 


\subsection{Como os gestores têm aprendido sobre a rotina de gerenciamento do processo produtivo dos pedidos dos clientes?}

Por meio da análise dos dados coletados foram encontradas quatro categorias que respondem à pergunta de pesquisa. Os resultados apontam que os gestores aprenderam sobre a rotina de gerenciamento dos pedidos vivenciando situações, buscando informações, interagindo com pessoas em seus ambientes de trabalho e também refletindo.

\subsubsection{Vivenciando situações}

A primeira categoria aponta que os gestores aprenderam sobre a rotina de gerenciamento dos pedidos vivenciando situações. Essa categoria refere-se a situações que ocorrem no ambiente de trabalho, algumas corriqueiramente, com certa regularidade, outras de maneira esporádica, como dificuldades ou problemas na execução da rotina. As situações corriqueiras são aquelas vivenciadas no dia a dia, na prática, à medida que os indivíduos estão executando, testando, observando as diversas ações que constituem a rotina de gerenciamento dos pedidos. Tais situações não devem ser confundidas com reações, ou seja, respostas automáticas a impulsos dados. As situações capazes de gerar aprendizado citadas pelos respondentes formam-se por um conjunto de atitudes ativas, não passivas, requerem um envolvimento por parte do ator.

A iniciativa dos atores é uma característica relevante para que as oportunidades de aprendizagem presentes nas situações corriqueiras sejam aproveitadas. Por exemplo, quando Gleyce assumiu a responsabilidade de guiar a reunião diária, não possuía as instruções de como deveria conduzi-la. À medida que executava a rotina, ela sentiu a necessidade de coletar mais informações sobre os pedidos. Ela explicou: “[...] fui eu que fui fazendo, fui percebendo a necessidade. [...] Pablo tem uma planilha no Excel que eu acompanho, eu pego na planilha de Pablo, lanço [a informação do pedido], vejo qual é o tipo de transporte para facilitar na reunião." Gleyce poderia ter optado por utilizar as informações da forma como estavam disponibilizadas, mas sua atitude perante a situação - observando a utilização de uma planilha do setor da Produção e inserindo informações complementares para criar uma planilha mais completa - fez com que ela aprendesse sobre a rotina, sendo capaz de aprimorá-la.

A observação diária da execução da rotina também contribuiu para aprendizagem dos gestores. Cícero, Gerente de Produção, afirmou que a base de seu conhecimento é a observação. Ele observa as ações diárias em seu setor e se questiona por que está acontecendo daquela maneira. Em suas palavras: "[...] a ideia é que eu encontre o porquê e a solução, depois que eu encontro a raiz do ocorrido. E isso vai trazer uma melhora, um melhor desempenho para a equipe." Conseguir observar em que situações a rotina foi executada de maneira diferente e conseguir tirar algo dessa situação que possa ser aplicado em outras, de modo que melhore o desempenho da rotina, é um desafio diário para os gestores, principalmente na Logística a na Produção, pois há diversas pessoas envolvidas na operação das atividades.

Além das situações frequentes e comuns no dia a dia dos respondentes, as situações adversas também foram citadas como fonte de aprendizagem sobre a rotina em questão. Essas são situações peculiares que fizeram com que os atores tivessem que pensar sobre a rotina, encontrar o motivo pelo qual não estava funcionando, identificar as causas dos problemas e buscar soluções. Pode-se citar como exemplo as reclamações de clientes. A satisfação do cliente e a entrega do pedido de acordo com o que foi negociado no ato da venda é a finalidade maior da rotina de gerenciamento dos pedidos. Se as falhas não forem percebidas ao longo de todo o processo produtivo, os produtos chegarão ao cliente com defeitos. Cícero, Gerente de Logística, relatou que, após receber algumas reclamações dos clientes com relação a avarias de produtos, ele e os funcionários do seu setor encontraram uma nova maneira de embalar o material que reduziu não só as reclamações por avaria, mas também os custos do processo. A solução encontrada ao analisarem o problema foi simples, os funcionários perceberam a necessidade de reforçar as embalagens dos produtos nas extremidades.

Assim, as situações vivenciadas, corriqueiras ou adversas, constituem uma oportunidade de aprendizagem sobre a rotina de gerenciamento dos pedidos. Não se afirma, porém, que essas situações são um meio concreto de construir o conhecimento acerca da rotina de gerenciamento dos pedidos porque sempre se deve considerar a disposição do ator para aprender sobre algo. A participação ativa do praticante, do gestor, é que de fato determina os meios pelos quais ele aprende ou não. Da mesma forma que suas atitudes são relevantes para aprenderem vivenciando situações, também o são para aprenderem à medida que buscam informações acerca da rotina de gerenciamento dos pedidos.

\subsubsection{Buscando informações}

A segunda categoria encontrada aponta que os gestores aprendem sobre a rotina de gerenciamento dos pedidos buscando informações. Essa categoria refere-se aos diversos tipos de informações pertinentes à execução da rotina. Algumas são de uso interno da Maxtil, como os prazos acordados, a quantidade de itens a serem fabricados, os itens em estoque, quais documentos devem ser enviados junto ao pedido e que procedimentos seguir. Outras informações não estão 
necessariamente dentro da empresa, essas geralmente orientam os gestores na criação de procedimentos ou indicam quais as melhores maneiras de gerenciar e de preparar a equipe para a execução da rotina.

Dentro da empresa - Maxtil - as informações podem ser buscadas no próprio sistema de informação e em documentos físicos ou virtuais. O banco de dados referente às informações necessárias para o gerenciamento dos pedidos pode ser acessado por meio de um Sistema Integrado de Gestão Empresarial - em inglês, Enterprise Resource Planning (ERP). O sistema de informação foi citado pelos respondentes como sendo um dos meios pelos quais eles aprenderam sobre a rotina. À medida que conheciam mais sobre o sistema utilizado, eles conseguiam perceber quais as informações e os procedimentos eram mais relevantes para que conseguissem executar a rotina. Gleyce, por exemplo, visualizou a possibilidade de utilizar o sistema para confirmar todos os pedidos que deveriam ser entregues no dia e percebeu que havia algumas inconsistências nos dados registrados. Ao corrigir essa falha, ela conseguiu ter informações mais confiáveis sobre os pedidos.

Outra importante fonte de informação são os e-mails enviados por Gleyce diariamente aos setores de Logística e da Produção após cada reunião, que informam como está o andamento de cada pedido. Todos os respondentes afirmaram que as informações compartilhadas por meio do correio eletrônico corporativo são relevantes para o desempenho da rotina. Nesses $e$-mails, a maior parte das informações é agrupada em uma planilha, o que possibilita a visualização de vários pedidos ao mesmo tempo. O Gerente de Produção, Carlos, afirmou que "[...] a comunicação é sempre via $e$-mail, em ralação à Produção e Vendas. E a planilha, ela é muito importante para nós da Produção, porque é na planilha que diz tudo: onde está o pedido, como está o pedido, para que dia está o prazo dele."

Algumas informações adquiridas em fontes externas à empresa também foram citadas pelos respondentes como um dos meios de aprendizagem sobre a rotina em questão. Fora da empresa, os funcionários encontram meios de enriquecer seu conhecimento fazendo cursos, lendo livros e revistas, pesquisando na internet, entre outros. Assim, conseguem manter-se atualizados em relação ao que está acontecendo no mercado e o que pode ser melhorado na execução da rotina. Isso contribui para que os praticantes sejam mais eficientes na execução de suas funções gerenciais. Cícero, por exemplo, citou que, por esses meios, ele consegue saber o que é que está acontecendo no mundo da Logística, quais as técnicas que estão sendo utilizadas e quais as que estão obsoletas. E complementa: “[aprendo] por todos os meios possíveis, internet, televisão, cursos. Minha vida é fazer esses cursos, sábado, domingo, para buscar informações que venham a me ajudar a desempenhar melhor o meu trabalho." Utilizando-se da internet, Cícero afirmou encontrar diversas informações em redes sociais e que "[...] às vezes, tem coisa que está tão fácil de você fazer, mas você nunca teve a ideia, outra pessoa chega e lança, 'olha, isso está acontecendo!'. Você acaba tentando fazer isso, aprimorando ou adaptando à sua realidade."

Os cursos de curta duração também possibilitam a aprendizagem dos gestores. Dentre todos os respondentes, Gleyce era a única que não possuía nenhuma experiência profissional ou formação acadêmica na área na qual atua hoje, no Setor de Vendas. Ela relatou que os cursos de curta duração foram importantes para que ela aprendesse como e o que falar aos clientes. Eles contribuíram para que ela melhorasse a sua comunicação, a negociação dos prazos de entrega e também as justificativas dos possíveis atrasos. Na sua função de Gerente de Vendas, essa capacidade de comunicação é essencial. Gleyce afirmou: "[aprendi] o que é que eu tenho que fazer, como é que eu tenho que tratar, se eu tiver algum problema como é que eu tenho que me redimir, como eu tenho que falar, o que eu tenho que retornar."

Nos casos citados, a atitude dos respondentes em buscar as informações, seja dentro ou fora da empresa, foi primordial para que a aprendizagem ocorresse. Além de aprender, buscando informações, os respondentes também relataram ter aprendido sobre a rotina ao interagir com pessoas. Essa é a categoria que será apresentada a seguir.

\subsubsection{Interagindo com pessoas}

A terceira categoria encontrada aponta que os gestores aprenderam sobre a rotina em questão interagindo com pessoas. As pessoas com as quais os praticantes interagem podem ser seus colegas de trabalho, pares, superiores ou subordinados, ou ainda podem ser clientes, fornecedores, parceiros da empresa, que de alguma forma conseguem compartilhar suas experiências e acrescentar algo no conhecimento que os praticantes possuem sobre a rotina.

A interação com pessoas específicas dentro da empresa, em situações específicas, foi considerada essencial pelos respondentes para que eles pudessem aprender sobre a rotina aqui estudada. Paulo, o Diretor, foi citado por todos os respondentes como sendo uma pessoa acessível e disposta a ajudar, por isso, eles afirmaram ter aprendido por meio da interação com ele. Carlos ressaltou: "Paulo é um cara muito inteligente, é um cara que eu admiro muito. [...] Então, parte da minha aprendizagem vem do Paulo, vem de pessoas que chegam com informações boas e eu vou [...] aprendendo." Cícero relatou que é difícil explicar como aprendeu sobre a rotina de gerenciamento dos pedidos porque foi um conhecimento construído com o tempo, na convivência, mas ressaltou "Paulo aqui ele 
cobra e me ajuda. Ele me chama e fala comigo: 'você precisa planejar seu pessoal, planejar seu trabalho'. Ele vai me orientando e me mostrando o caminho que eu devo seguir e nisso eu vou aprendendo."

A reunião diária é uma das situações peculiares na qual é possível aprender por meio da troca de opiniões. Cícero explica que nas reuniões “" [...] todos participam do processo de todos, visualizando e interferindo verbalmente quando isso é preciso, dando opinião. [...] Isso é importante, a interação de setores, a troca de ideia, de conhecimento e a crítica que não seja apenas por criticar, mas que seja visando o bem geral do todo que é a empresa que você trabalha, é sempre válida." Assim, à medida que os praticantes conversam uns com os outros sobre a rotina, eles conseguem aprimorar seu conhecimento sobre ela, pois isso lhes permite visualizar suas atividades considerando o ponto de vista de outras pessoas. Gleyce explicou que "[...] na reunião é possível identificar se a gente está fazendo alguma coisa errada, com maior tranquilidade. Porque é mais fácil terceiros notarem o que eu estou fazendo de errado, do que eu mesma identificar." Um dos benefícios proporcionados pela integração, a possibilidade de identificar falhas em partes isoladas antes que elas prejudiquem o todo.

É relevante considerar que a disposição do praticante para ouvir é primordial para que ele possa aprender interagindo com pessoas tanto dentro quanto fora da empresa. Geralmente, as interações realizadas com pessoas que atuam em outras empresas, especialmente as que se encontram dentro da mesma cadeia produtiva, como fornecedores e clientes, proporcionam novos conhecimentos. A construção desses conhecimentos é fortemente baseada na troca de experiências. Um exemplo interessante de um novo conhecimento adquirido nessas interações foi em relação à utilização do transporte marítimo de mercadorias. Tal conhecimento se faz necessário para ampliar a atuação da Maxtil e interferirá diretamente na rotina de gerenciamento dos pedidos, especialmente na questão da entrega. Cícero explicou que, hoje, a Maxtil trabalha com transporte rodoviário e aéreo, mas tem um terceiro segmento, o marítimo, que provavelmente será utilizado no futuro. Ele afirmou que "[...] acaba ligando para essas empresas só em nível de conhecimento, só para colher informações, saber como funciona. Hoje a gente tem um leque de informações a respeito desse tipo de transporte porque quando a gente precisar a gente vai estar apto, [...] por essa troca de informação."

Nesse sentido, as interações que ocorrem dentro e fora do ambiente da empresa na qual os praticantes atuam constituem um meio de aprendizagem sobre a rotina de gerenciamento dos pedidos. Além de aprender interagindo, os respondentes também afirmaram que é possível ampliar seus conhecimentos acerca da rotina estudada quando refletem sobre ela. Tal categoria será apresentada a seguir.

\subsubsection{Refletindo}

A última categoria encontrada aponta que os gestores aprendem sobre a rotina de gerenciamento dos pedidos refletindo sobre as atividades e decisões inerentes ao seu desempenho. A reflexão sobre novas possibilidades é um dos meios pelos quais todos os respondentes afirmaram conseguir aprimorar a execução da rotina de gerenciamento dos pedidos. A capacidade de avaliar o que acontece no dia a dia por meio da reflexão faz com que os gestores enxerguem novas maneiras de exercer a rotina. Essas novas possibilidades funcionam como um conjunto de alternativas para resolver possíveis problemas, para preencher lacunas de informações ou, ainda, para tornar mais eficientes as ações dos gestores e suas equipes.

Uma questão fortemente ligada à reflexão sobre novas possibilidades é a sensação por parte do gestor de que sempre é possível fazer melhor. Cícero afirmou pensar constantemente em como pode reorganizar sua equipe para que o setor de Logística seja mais rigoroso em relação à avaliação da qualidade dos produtos, em especial com aqueles que passam pelo processo de galvanização a fogo. Ele explica que "[...] é um problema muito grande, é um material que vai para a obra e a gente tem que dar de garantia trinta anos [...]. Hoje tem um foco que é melhorar e capacitar pessoas [para a função] de acabamento, estudando." Para Cícero, o processo de reflexão o ajuda a avaliar "[...] tudo o que acontece a cada dia, seja bom, seja ruim, seja para melhorar, implementar, eu sempre estou refletindo. [...] É um processo diário.” Ainda, Carlos afirmou que frequentemente reflete sobre o que tem que ser feito, analisando como pode fazê-lo. Em sua entrevista, Carlos ponderou sobre o funcionamento da fábrica explicando: “[...] hoje eu fico refletindo no que é que pode ser feito para melhorar. Tudo o que eu falo é voltado para a produção, para melhorar a nossa produtividade." Em outras palavras, a reflexão pode ser comparada a um processo constante de busca por novas maneiras de enxergar a rotina que se exerce, possibilitando que o praticante projete melhorias.

O objetivo da reflexão geralmente é encontrar uma maneira, nova ou mais eficiente, de exercer a rotina. Nesse sentido, o comprometimento de cada gestor reflete seus objetivos e pode contribui com sua aprendizagem. Pablo diz que chega a sonhar com o que tem que ser feito e com os pedidos que têm que ser entregues. "Eu sonho muito com isso aqui, sabia? [...] Eu fico muito preocupado com os pedidos que têm que sair. Quando não sai, eu fico muito preocupado. [...] Mas a gente sempre reflete, 'se mudar, será que fica melhor?'. Estou sempre 
pensando assim." Como resultado dessa reflexão em busca de melhorias Pablo conseguiu aprimorar o gerenciamento dos pedidos ao longo do processo fabril. Segundo ele, foi uma medida simples, mas que ajudou bastante. Ele acrescentou algumas colunas à planilha que eles utilizam no setor da Produção apontando o setor da fábrica no qual cada pedido se encontra, corte, dobra, serralharia ou solda.

A reflexão demanda do ator a habilidade de avaliar as situações, ponderar sobre as necessidades e as possibilidades. Nesse sentido, o desafio do gestor é tornar-se capaz de transformá-la num hábito, ou seja, pensar constantemente sobre o que foi feito ou como poderia ser feito, avaliando e reavaliando as ações praticadas, os procedimentos utilizados e o resultado alcançado. Assim, argumenta-se que a reflexão e os demais meios de aprendizagem aqui identificados contribuem para a aprendizagem do gestor sobre a rotina de gerenciamento dos pedidos, fornecendo subsídios para que o gestor aprimore o seu desempenho.

\section{Discussão e implicações para a prática}

Uma das principais abordagens utilizadas no desenvolvimento deste estudo foi a de rotinas organizacionais. Feldman (2000, p. 625) argumenta que "[...] o processo de engajar-se numa rotina organizacional pode ser um processo de aprendizagem." Para ela, “[...] rotinas organizacionais envolvem pessoas fazendo coisas, refletindo sobre o que estão fazendo, e fazendo coisas diferentes (ou fazendo as mesmas coisas diferentemente) como um resultado da reflexão."

A aprendizagem por meio da vivência de situações corriqueiras é caracterizada pela capacidade de observar a execução de atividades e de algumas circunstâncias que se repetem, tornando-as comuns ao dia a dia do gestor. A repetição, por sua vez, é uma das principais características de uma rotina. De acordo com Feldman \& Pentland (2003, p. 103), a repetição evidencia o aspecto performativo da rotina, enquanto que a existência de um padrão de ações (como as representadas na Figura 1) representa seu aspecto ostensivo. Ainda, a execução da rotina estudada envolvia múltiplos participantes. De acordo com Feldman \& Pentland (2003, p. 104), essa característica “[...] assegura que o aspecto ostensivo da rotina - sua parte estrutural - não pode ser monolítico ou indiferenciado, exceto talvez em casos triviais." Isso corrobora os resultados encontrados, uma vez que essas características foram identificadas na rotina de gerenciamento dos pedidos e os praticantes envolvidos demonstravam conhecer seu aspecto ostensivo, sendo esse guia para a execução das atividades dos gestores.

Segundo a definição de rotina de Feldman \& Pentland (2003), a existência de artefatos contribui para sua manutenção. Os autores citados explicam, entretanto, que a existência do artefato que contém a definição ostensiva sem a performance em curso, torna-o sem sentido. Ou seja, é necessário que haja uma aceitação por parte do praticante em relação aos procedimentos-padrão adotados pela organização. Assim como no estudo de Vitório (2008), os gestores aqui entrevistados afirmaram que a adoção de rotinas e procedimentos - nos casos estudados por

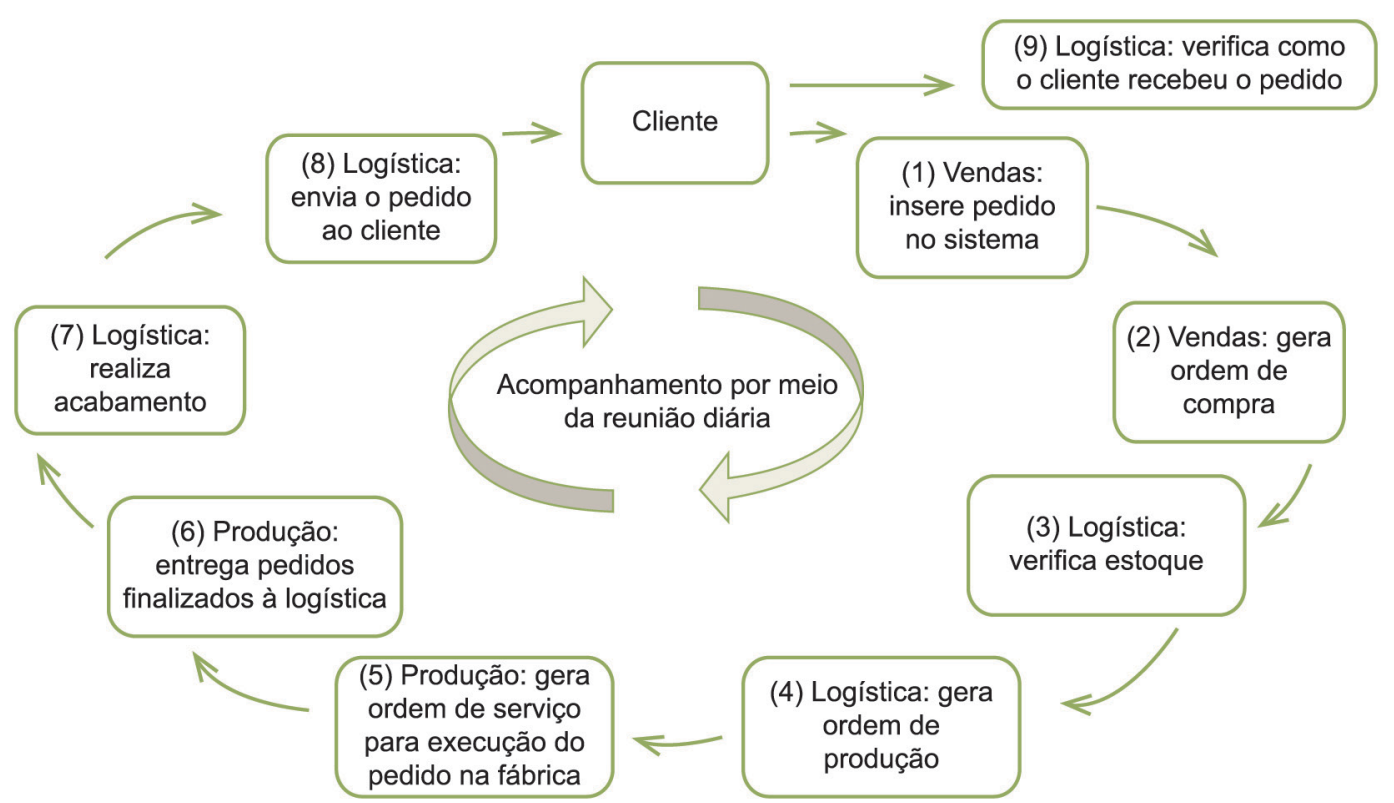

Figura 1. Representação das etapas inerentes à rotina de acompanhamento do pedido. Fonte: Elaborado pelos autores 
Vitório (2008), normas ISO; no caso da Maxtil, o CRCC, que lhes permitiu fornecer para a Petrobras e outras empresas ligadas a ela - contribui para sua aprendizagem. Esse processo permite que os gestores conheçam os padrões de qualidade exigidos pelos clientes e visualizem que ações são necessárias para se cumprir os requisitos solicitados. Assim, utilização de tais normas serviu como um guia, uma explicação ou uma referência para os praticantes da Maxtil. E essas são funções do aspecto ostensivo da rotina segundo Feldman \& Pentland (2003).

Os pesquisadores observaram que era possível e até desejável que os gestores buscassem maneiras novas ou mais adequadas de executar suas rotinas. A busca pelo aprimoramento da rotina é uma evidência da utilização da capacidade de agência (Giddens, 2009) dos atores que estão envolvidos com a sua execução. De acordo com a análise dos dados, os gestores aqui estudados aprenderam por meio da reflexão sobre as situações que vivenciavam buscando corrigir as falhas, prevenir os erros, melhorar o controle, enfim, aprimorar a execução da rotina. Wilson \& Jarzabkowski (2004) afirmam que os praticantes da estratégia podem enxergar três dimensões de agência, dentre as quais se encontra a prática-avaliativa, que os autores afirmam envolver atores que reflitam, que sejam "[...] capazes de entender suas ações atuais dentro do contexto de ações passadas e de aspirações futuras, e que façam a medição entre as duas coisas de forma a poder desafiar e transformar a prática existente." (Wilson \& Jarzabkowski, 2004, p. 15). Corroborando, Feldman \& Pentland (2003, p. 109) argumentam que é " [...] a agência é evidente na escolha das ações de cada participante e no automonitoramento reflexivo dessas ações." Nesse sentido, o aperfeiçoamento no desempenho da rotina reforça a capacidade de mudança que a rotina contém, reforçando os estudos realizados por Feldman (2000), Feldman \& Pentland (2003) e Pentland \& Feldman (2005).

O estudo realizado por Gonzalez \& Martins (2011) fortalece as evidências em torno da relação positiva existente entre a aprendizagem e a melhoria de rotinas ligadas à gestão da qualidade. Para os autores, "[...] a criação e a manutenção de um ambiente que estimule a aprendizagem é um importante aspecto relacionado à sustentabilidade dos programas de melhoria." (Gonzalez \& Martins, 2011, p. 484). É interessante a descrição feita pelos autores de como as empresas do setor automobilístico estudadas procuravam tornar a filosofia da melhoria contínua uma rotina, englobada na estratégia da empresa, utilizando-se de programas de incentivo à participação do funcionário. A existência de grupos de trabalho, tanto de rotina quanto de melhoria, segundo os autores, "[...] promove o desenvolvimento de uma linguagem comum entre os indivíduos que compõem os grupos, aumentando o potencial de assimilação e geração de novos conhecimentos, intensificando o potencial para o desenvolvimento de melhorias." (Gonzalez \& Martins, 2011, p. 484). Comparando tal afirmação com os resultados aqui encontrados, pode-se dizer que os gestores que se reúnem diariamente para exercer a rotina de acompanhamento de pedido formam esse grupo de trabalho e conseguem compartilhar e gerar novos conhecimentos em busca de melhorias na execução da rotina e consequentemente na qualidade final para o cliente.

Ressalta-se, nesse ponto, que a abordagem da aprendizagem pela experiência (Dewey, 1938) defende que a aprendizagem é um processo que não ocorre apenas no indivíduo, mas, sim, na relação existente entre ele e o ambiente no qual ele está inserido - que inclui a organização, as pessoas, os significados que elas compartilham, os artefatos que descrevem suas rotinas, entre outros. Nesse sentido, a aprendizagem dos gestores sobre as rotinas que exercem também não é um fenômeno interno a eles, mas sim algo que ocorre de maneira relacional, na qual indivíduo e ambiente interferem-se mutuamente formando as situações. Tal influência foi observada no processo de aprendizagem dos gestores estudados por Gonzalez \& Martins (2011) - setor automobilístico - assim como na Maxtil - cadeia produtiva de Petróleo e Gás e da Indústria Naval. A Maxtil passou por diversas mudanças impostas pela necessidade de atender às novas demandas do mercado por melhor qualidade e maior quantidade de produção com a chegada da Refinaria de Abreu e Lima, por exemplo. A criação da rotina aqui estudada, inclusive, é fruto dessas demandas do ambiente.

A formação de propósitos também se mostrou relevante para a aprendizagem dos gestores aqui estudados. Dewey (1938) argumenta que tal formação constitui uma operação intelectual bastante complexa. Segundo ele, há três requisitos ou critérios necessários para que o propósito surja. É possível estabelecer uma comparação entre os critérios para a formação de propósitos apresentados e os resultados encontrados neste estudo. O Quadro 1 sintetiza essas relações apontando quais são esses requisitos e como os gestores os aprenderam.

Dewey (1938) explica que exercitar a observação é uma condição para a transformação de um impulso em um propósito. Porém, ele ressalta que "[...] a observação por si só não é suficiente. Nós temos que entender o significado do que vemos, ouvimos e tocamos. Esses significados consistem das consequências que resultarão quando o que é visto for posto em prática.” (Dewey, 1938, p. 68). No estudo realizado, a observação da execução das atividades inerentes à rotina de gerenciamento dos pedidos foi citada pelos gestores como sendo uma ação que lhes permitia analisar as situações que eles estavam vivenciando, o que possibilitou melhor compreensão 
Quadro 1. Como os gestores aprenderam os requisitos para a formação de propósitos.

\begin{tabular}{|c|c|c|}
\hline $\begin{array}{l}\text { Requisitos para } \\
\text { surgimento do } \\
\text { propósito }\end{array}$ & Como aprenderam & Ações \\
\hline $\begin{array}{l}\text { Observação das } \\
\text { condições }\end{array}$ & Vivenciando situações & $\begin{array}{l}\text { Observar como a própria rotina é desempenhada e considerar as } \\
\text { críticas e advertências recebidas }\end{array}$ \\
\hline \multirow{2}{*}{$\begin{array}{l}\text { Conhecimento de } \\
\text { situações similares } \\
\text { que ocorreram no } \\
\text { passado }\end{array}$} & Buscando informações & Procurar documentos, manuais e registros que auxiliem na memória \\
\hline & $\begin{array}{l}\text { Interagindo com } \\
\text { pessoas }\end{array}$ & Conversar com pessoas que já passaram por situações similares \\
\hline $\begin{array}{l}\text { Julgamento do que } \\
\text { foi observado e } \\
\text { recordado }\end{array}$ & Refletindo & Ponderar o que foi observado e as informações obtidas \\
\hline
\end{tabular}

em relação ao aspecto ostensivo da rotina, ao atribuir novos significados ao que foi observado ou mesmo reconstruí-los.

Também é necessário que os atores envolvidos na formação de um propósito tomem a decisão de agrupar as informações necessárias para que possam julgar e compreender melhor as rotinas que exercem. Neste estudo, os respondentes conseguiam obter parte desses insumos por meio da busca de informações, recorrendo aos registros realizados anteriormente, ao longo da execução das atividades inerentes à rotina ou interagindo com pessoas dentro e fora da empresa. Esses achados convergem com os apresentados nas pesquisas de Santos (2009), Vitório (2008) e Lucena (2001). As redes de relacionamento que são criadas por meio dessas interações, segundo o resultado das pesquisas realizadas pelos autores citados, colaboram com o processo de aprendizagem dos gestores, sendo um meio de obter informações relevantes para compreender o mercado, tomar decisões ou legitimar ideias.

O desenvolvimento das capacidades de julgamento e compreensão implica, de acordo com Dewey (1938, p. 84), essencialmente, no crescimento da habilidade de formular propósitos e de selecionar e organizar meios para sua realização. Isso evidencia a importância da reflexão como sendo um dos meios pelos quais os gestores podem desenvolver tais capacidades. A reflexão é inerente à capacidade de analisar situações e foi desenvolvida pelos gestores aqui estudados durante e após a execução da rotina. Aliás, o próprio surgimento da rotina é fruto de um momento de reflexão do Diretor, Paulo. O evento da Virada de Mesa pode ser considerado uma situação de inquiry (Dewey, 1938; Miettinen, 2002), na qual os hábitos não funcionam, gerando uma incerteza, um problema, fazendo com que surja a demanda por um pensamento reflexivo.

Os meios de aprendizagem aqui apresentados podem ser comparados aos "mecanismos de aprendizagem" do estudo realizado por Loiola et al. (2011), com empresas da fruticultura irrigada do Baixo Médio
São Francisco. De acordo com os autores citados, os mecanismos de aprendizagem utilizados com maior frequência pelos funcionários pesquisados são: "ajuda de colega", "por conta própria" e "orientação do supervisor". Na categoria controle da qualidade, os autores apontam que o mecanismo "orientação do supervisor" é o mais relevante, pelo fato de tal ensinamento exigir conhecimentos técnicos, os quais aparentam ser apenas do domínio do supervisor (Loiola et al., 2011). No caso dos gestores da Maxtil, a orientação do diretor, Paulo, era significativa, especialmente na implementação da rotina de gerenciamento dos pedidos e também para a geração de uma cultura que prezasse pela qualidade.

\section{Conclusões}

Esta pesquisa foi realizada com o intuito de compreender como ocorre a aprendizagem dos gestores sobre a rotina de gerenciamento dos pedidos. Os resultados apontaram que os gestores aprenderam por meio da vivência de situações corriqueiras, possibilitada pela capacidade de observar a execução de atividades e de algumas circunstâncias que se repetiam, tornando-se comuns ao dia a dia do gestor.

Os resultados deste artigo contribuem para a agenda de pesquisa da estratégia como prática proposta por Whittington (2002, 2006), em relação ao estudo das práticas e também sobre como os profissionais se preparam - aprendem - para exercer a práxis de maneira eficaz. A utilização dos conceitos de Dewey (1938) dentro de um contexto organizacional ajudou a fortalecer as ligações teóricas entre os campos da aprendizagem e da estratégia. O estudo das práticas de estratégia utilizando o conceito de Feldman \& Pentland (2003) de rotinas organizacionais permitiu compreender como ocorre a aprendizagem sobre elas e também como de fato são utilizadas pelos gestores em seu dia a dia, num trabalho de constante formação e na execução da estratégia. Além disso, os resultados evidenciaram aspectos da organização do trabalho humano que se relacionam com itens da logística e do planejamento e controle da produção. 
Entende-se que as contribuições deste estudo podem ir além da construção de um conhecimento teórico específico sobre a aprendizagem de gestores. É possível que os resultados aqui encontrados sejam relevantes também para os gestores que atuam em empresas fornecedoras [em potencial] de bens para a cadeia produtiva estudada, tanto para os que participaram desta pesquisa, quanto para outros que possam se interessar pelo tema.

Espera-se que os resultados encontrados possam ser aprimorados e sirvam como base para o desenvolvimento de estudos futuros. Nesse sentido, sugere-se que esses descrevam o processo de aprendizagem de gestores que atuem em empresas fornecedoras da cadeia produtiva em questão em outros estados brasileiros, fornecendo subsídios para um estudo comparativo; utilizem o método de observação a fim de captar detalhes sobre o desempenho das rotinas, para constatar se há ou não uma variação na performance dos praticantes envolvidos; e investiguem como o processo de aprendizagem dos gestores sobre suas rotinas contribui para a organização obter certificações de qualidade do tipo ISO ou OHSAS e qual a importância dessas para tornar-se fornecedora da cadeia produtiva aqui estudada.

\section{Agradecimentos}

Nosso muito obrigado a Paulo Giovani, Diretor e proprietário da Maxtil. Sem sua disponibilidade e ajuda a realização deste estudo não seria possível. Também aos demais respondentes desta investigação - Gleyce, Cícero, Pablo, Carlos e Sérgio - que compartilharam conosco suas experiências e concederam seu tempo e sua atenção, agradecemos as contribuições. Por fim, nosso agradecimento à Fundação de Amparo à Ciência e Tecnologia (FACEPE), pelo apoio financeiro concedido para a realização desta pesquisa.

\section{Referências}

Dewey, J. (1938). Experience and education. New York: Touchstone.

Easterby-Smith, M., Snell, R., \& Gherardi, S. (1998). Organizational learning: diverging communities of practice. Management Learning, 29(3), 259-272. http:// dx.doi.org/10.1177/1350507698293001.

Elkjaer, B. (2004). Organizational learning: the 'third way'. Management Learning, 35(4), 419-434. http://dx.doi. org/10.1177/1350507604048271.

Elkjaer, B. (2009). Pragmatism: a learning theory for the future. In K. Illeris (Ed.), Contemporary theories of learning: learning theorists - in their own words (Cap. 5, pp. 74-89). New York: Routledge.

Feldman, M. S. (2000). Organizational routines as a source of continuous change. Organization Science, 11(6), 611-629. http://dx.doi.org/10.1287/orsc.11.6.611.12529.

Feldman, M. S., \& Pentland, B. T. (2003). Reconceptualizing organizational routines as a source of flexibility and change. Administrative Science Quarterly, 48(1), 94-118. http://dx.doi.org/10.2307/3556620.

Giddens, A. (2009). A constituição da sociedade (Á. Cabral, Trad., 3 ed.). São Paulo: WMF Martins Fontes.

Golsorkhi, D., Rouleau, L., Seidl, D., \& Vaara, E. (Eds.). (2010). Cambridge handbook of strategy as practice. Cambridge: Cambridge University Press. http://dx.doi. org/10.1017/CBO9780511777882.

Gonzalez, R. V. D., \& Martins, M. F. (2011). Melhoria contínua e aprendizagem organizacional: múltiplos casos em empresas do setor automobilístico. Gestão \& Produção, 18(3), 473-486. http://dx.doi.org/10.1590/ S0104-530X2011000300003.

Jarvis, P. (1987). Meaningful and meaningless experience: toward an analysis of learning from life. Adult Education Quarterly, 37(3), 164-172. http://dx.doi.org/10.1177/0 001848187037003004.

Jarzabkowski, P. (2004). Strategy as practice: recursiveness, adaptation, and practices-in-use. Organization Studies, 25(4), 529-560. http://dx.doi.org/10.1177/0170840604040675.

Jarzabkowski, P., \& Whittington, R. (2008). A strategy-aspractice approach to strategy research and education. Journal Of Management Inquiry, 17(4), 282-286.

Jarzabkowski, P., Balogun, J., \& Seidl, D. (2007). Strategizing: the challenges of a practice perspective. Human Relations, 60(1), 5-27. http://dx.doi.org/10.1177/0018726707075703.

Johnson, G., Langley, A., Melin, L., \& Whittington, R. (2007). Strategy as practice: research directions and resources (Cap. 1, pp. 26-27). Cambrige: Cambrige University Press. http://dx.doi.org/10.1017/CBO9780511618925.

Lave, J., \& Wenger, E. (1991). Situated learning: legitimate peripheral participation. New York: Cambridge University Press. http://dx.doi.org/10.1017/CBO9780511815355.

Loiola, E., Pereira, M. E., \& Gondim, S. (2011). Aprendizagem e mecanismos de aprendizagem de trabalhadores em empresas da fruticultura irrigada do Baixo Médio São Francisco. Gestão \& Produção, 18(1), 91-104. http:// dx.doi.org/10.1590/S0104-530X2011000100007.

Lucena, E. A. (2001). A aprendizagem profissional de gerentes-proprietários do setor de varejo de vestuário de Florianópolis (Tese de doutorado). Universidade Federal de Santa Catarina, Florianópolis.

Merriam, S. B. (2009). Qualitative research: a guide to design and implementation (2 ed.). San Francisco: Jossey-Bass.

Merriam, S. B., \& Caffarella, R. S. (1999). Key theories of learning. In S. B. Merriam, R. S. Caffarella \& L. M. Baumgartner. Learning in adulthood: a comprehensive guide (2 ed., Cap. 11, pp. 248-256). San Francisco: Jossey-Bass.

Miettinen, R. (2002). About the legacy of experiential learning. Thresholds in Education, 2002, 11-18.

Minayo, M. C. S. (Org.). (2004). Pesquisa social: teoria, método e criatividade. Petropólis: Vozes.

Patton, M. (2002). Qualitative research and evaluation methods (3 ed.). Thousand Oaks: Sage Publications.

Pentland, B. T., \& Feldman, M. S. (2005). Organizational routines as anit of analysis. Industrial and Corporate Change, 14(5), 793-815. http://dx.doi.org/10.1093/ icc/dth070. 
Santos, C. I. (2009). A aprendizagem de executivos de organizações do setor metalmecânico e que atuam como fornecedoras da cadeia produtiva de petróleo e gás natural em Pernambuco (Dissertação de mestrado). Universidade Federal de Pernambuco, Recife.

Schwandt, T. A. (1994). Constructivist, interpretivist approaches to human inquiry. In N. K. Denzin \& Y. S. Lincoln (Eds.), Handbook of qualitative research (Cap. 7, pp. 118-137). Thousand Oaks: Sage Publications.

Vitório, S. B. C. (2008). A aprendizagem de gestores de empresas de incorporação da Região Metropolitana de Recife por meio de experiências e reflexões: um estudo de múltiplos casos (Dissertação de mestrado). Universidade Federal de Pernambuco, Recife.

Whittington, R. (1996). Strategy as practice. Long Range Planning, 29(5), 731-735. http://dx.doi. org/10.1016/0024-6301(96)00068-4.

Whittington, R. (2001). Learning to strategise: problems of practice. SKOPE Research Paper, 20, 1-28.

Whittington, R. (2002). Practice perspectives on strategy: unifying and developing a field. Academy of Management Proceedings, 2002(1), C1-C6.
Whittington, R. (2003). The work of strategizing and organizing: for a practice perspective. Strategic Organization, 1(1), 117-125. http://dx.doi.org/10.117 $7 / 1476127003001001221$.

Whittington, R. (2006). Completing the practice turn in strategy research. Organization Studies, 27(5), 613-634. http://dx.doi.org/10.1177/0170840606064101.

Whittington, R. (2007). Strategy practice and strategy process: family differences and the sociological eye. Organization Studies, 28(10), 1575-1586. http://dx.doi. org/10.1177/0170840607081557.

Whittington, R. (2010). Giddens, structuration theory and strategy as practice. In D. Golsorkhi, L. Rouleau, D. Seidl \& E. Vaara (Eds.), Cambridge handbook of strategy as practice (Cap. 7, pp. 109-126). Cambridge: Cambridge University Press.

Wilson, D. C., \& Jarzabkowski, P. (2004). Pensando e agindo estrategicamente: novos desafios para a análise estratégica. Revista de Administração de Empresas, 44(4), 11-20.

Yin, R. K. (2005). Estudo de caso: planejamento e métodos (3 ed.). Porto Alegre: Bookman. 